and the anterior in an oblique direction downwards and forwards to a little below the lowest point of the prolapsed bladder, a male catheter being introduced, beak downwards, so as to guard against wounding the bladder.

Fig. 2, V, T, represents the line of incision, and the wedge-like excision of the flap; the mucous membrane lining the interior of the cervix being then stitched to that covering its external or vaginal surface. In this way the profuse hremorrhage which usually accompanies the operation is arrested, and early healing promoted.

In Mrs. W-'s case the plan adopted was somewhat different. The patient being laid on her left side and Sims' speculum placed behind the cervix in the posterior cul-desac, a grooved director was introduced well into the cervix, and by a curved bistoury the posterior wall was incised high up as far as V, Fig. 3, in the median line ; the front wall was then divided up to $\mathrm{T}$, and the lateral flaps cut off in an oblique direction from $\mathrm{V}$ to $\mathrm{T}$, and in the wedge-shaped manner recommended by Schroeder. Catgut sutures were then introduced, a roll of bandage was placed behind the stump, and a perineal bandage firmly applied. No hæmorrhage having occurred during the night, ordinary glycerine was subsequently applied, and the incisions healed by first intention, except at the highest point behind, where a granulating surface made its appearance, but this gave very little trouble, and also healed in a few weeks. Involution took place rapidly as far as the remainder of the cervix was concerned, but the rest of the uterus continued to increase in size; a copious discharge from the interior of the uterus persisted, but the metrorrhagia disappeared.

Three weeks after the operation $I$ allowed the patient to get up, and making an examination a week afterwards, on account of a complaint of backache, I found that retroflexion had again taken place, or rather retroversion, for there was now no cervix to speak of. This condition required reduction, and the introduction of a pessary.

Six months after the operation I found that the body of the uterus had grown to a great size, so that the fundus could be very distinctly felt by simple abdominal palpation; that although the pessary had been removed, a recurrence of the retroversion had not taken place, probably on account of the great size of the uterus; that she suffered little inconvenience from the discharge, and none at all from hremorrhage, and that she could walk about and do her housework without any of her former symptoms.

On May 20th, 1879, I again examined Mrs. W-. The vagina was healthy, and there was no discharge from the os. Along the front of the vagina was a prominent ridge, firm, of the consistence of uterine structure, continnous with the body of the uterus above, and terminating below in a blunted point, being, in fact, the remainder of the elongated cervix. The fundus was retroverted, but, being now very much reduced in size, gave rise to no symptoms, unless after an unusually long walk or other severe exertion, when she suffers a little from sacral pain and weight in the pelvis.

The formation of lateral instead of antero-posterior flaps, gives, I think, more facility for the introduction of stitches, and certainly allows of more extensive removal of cervix

Fuddersfield.

\section{INTUSSUSCEPTION ; INFLATION WITH AIR ; RECOVERY.}

\section{BY T. D. RANSFORD, F.R.C.S. ENG.}

ON August 12th, 1879, I was called to see A. H--, a fine, healthy male child, eleven months old. After a hearty breakfast, of which fish was one of the ingredients, he was taken suddenly ill, was very sick and pale, and seemed to have much pain in the bowels. He was taken to a chemist, who administered a powder of rhubarb and mercury, after which the child began to pass blood per anum, was collapsed and in much pain. When $I$ saw the child he was in the above condition, passing much blood and mucus. On examining the abdomen, a sausage-shaped tumour, about two and a half inches in length, was felt in the right hypochondriac and right lumbar regions; the rectum was dilated, but contained nothing but blood and mucus, which came away in large quantities on withdrawing the finger from the anus.
Ordered half a minim of tincture of opium every two hours. My friend Dr. Campbell, surgeon to the Northern Hospital Liverpool, saw the child with me in the evening, and agreed with me as to the nature of the case and the treatment. We injected by means of Higginson's syringe a pint of olive oil, which soon came back mixed with blood and mucus. As the child still continued to be very sjck and in much pain, we ordered a grain of compound ipecacuanha powder every second hour.

On August 13th I found the child had passed a very rest. less night, vomiting not quite so frequent, and had passed less blood; so, after fastening the end of the enema to a pair of common house bellows, I proceeded to inflate it per anum. On withdrawing the tube it was covered with blood and mucus; no frecal matter; no noticeable result. Called in the afternoon, about five or six hours after first visit, and again inflated the child; this time, on withdrawing the tube, the end was covered with fluid fæces, some had also been sucked up into the bellows. To continue the compound ipecacuanha powder. On the 14th the child had passed a good night, seemed quite free from pain; sickness had stopped; no tumour could now be felt through the abdominal walls; bowels had not been opened; seemed weak and flabby, but otherwise well.

16th.-The little patient has continued to improve in ap. pearance and gradually gained strength. This morning passed a copious but normal stool. Dover's powder discon. tinued, and child pronounced quite well.

Remarks. - The sudden onset of pain and sickness in a previously healthy child, followed by the passage of blood and mucus, with the presence of a sausage-shaped tumour felt through the abdominal walls, left no doubt in my mind as to the nature of the case, and I asked Dr. Campbell to see it, partly to satisfy the parents, partly because it was an interesting case and one I thought he would like to see, and partly because it is only little more than two years ago since I published a very similar case in THE LANCET.

liverpool.

A NEW

\section{PLASTER SPLINT FOR GENU VALGUM AND INFANTILE PARALYSIS AFFECTING} THE EXTREMITIES.

\section{BY BERNARD ROTH, F.R.C.S. ENG.}

I HAvE treated several cases of moderate genu valgum very successfully by means of the following splint:-The limb, surrounded with cotton-wool, is covered with a layer of plaster-of-Paris bandage (as used for Sayre's jacket); a thin wooden splint of the right length is then applied to the outer aspect of the limb, and held firmly by an assistant, who endeavours to make the limb as straight as possible, while another layer of plaster-of-Paris bandage is wound round as tightly as possible. Generally three ordinary prepared plaster-roller bandages are sufficient. The patient may either keep this bandage on permanently for two or three months, or it may be opened when quite dry next day by a longitudinal incision along its inner aspect. The plaster is first carefully divided by an ordinary pair of vine-dresser's shears, and then the cotton-wool by scissors. The whole plaster splint may now be taken from off the limb, and its inside lined with chamois leather, to keep the cotton-wool in place, and the outside covered with stouter leather, into which a series of boot-hooks are to be fixed along each edge. Any bootmaker is able to do this. A very light leg splint is thus obtained, weighing from one to two pounds, which is readily put on and fixed by an ordinary leather lace by means of the hooks.

This splint is not only far better than any leg-iron with straps, from its fitting the limb accurately, but also much more economical, as the materials used are inexpensive, costing three or four shillings, exclusive of the bootmaker's work, which may even be dispensed with, and the splint covered at home. I have used a similarly constructed splint in many cases of infantile paralysis, where the knees could not be kept extended without support; for these cases the piece of wood was applied to the back of the leg and the bandage cut open in front. In several cases where both legs were affected, and where they were constantly cold and 
bluish from defective circulation, these splints have been worn daily for many months with much benefit, enabling patients to walk about who were previously quite helpless, and with the great additional advantage of keeping the limbs comfortably warm by means of the cotton-wool with which they are lined. Even when tightly laced, the presstre is so equably distributed that hardly any marks are found on the skin when the splints are removed at night, or for allowing the limbs to be rubbed or otherwise acted upon. Brighton.'

\section{STRANGULATED FEMORAL HERNIA OF FIVE DAYS' DURATION; OPERATION ; RECOVERY.}

BY W. A. ROSS, M.R.C.S., \&c.

THE chief features of this case seem to me to be the length of time-five days-that the hernia had been strangulated, also the age and weakly and emaciated condition of the patient at the time of operation, which I only performed as a last resource. She was for two hours under the influence of chloroform.

About 9 P.M. on Feb. 12th, 1879, I was called to see Mrs. S-, aged seventy. In answer to my inquiries I learnt that for more than twenty years she had been the subject of femoral hernia, which, for some reasons or other, she had never mentioned either to her husband or daughters. From time to time she had had attacks of colicky pains in the abdomen and constipation, which generally passed off in a few days, leaving her very weak. Sometimes she had been obliged to call in a medical man. When I saw her she had been suffering for four days previonsly with severe abdominal pain, and obstinate vomiting and constipation. She was somewhat emaciated, with pinched features and a hard and wiry pulse.

On examination I found a strangulated femoral hernia in the left groin, about the size of an egg, very painful, tense, and hard. I tried taxis and the warm bath with opium, but could not effect reduction. As the symptoms were not extremely urgent I administered a dose of morphia and left her.

The following morning, with the assistance of Messrs. Dustan and Seymour, A.M.D., the patient was put under the influence of chloroform, and all our efforts at reduction proving unavailing, I cut down on the sac in the usual way, and divided the stricture, and at the same time broke down some adhesions which had formed between the sac and the femoral ring. The contents of the sac, consisting of omentum in which was concealed a small knuckle of intestine, being in a tolerably healthy condition, were returned into the abdomen, and the wound closed with four sutures, and dressed with carbolic oil.

The further progress of the case was very satisfactory. In three weeks the wound was perfectly healed, with the exception of two small granulations where the sutures had been. Alderney.

\section{NOTE ON THE DANGER ATTENDING THE USE OF SALICYLIC ACID IN ACUTE RHEUMATISM.}

BY T. J. MACLAGAN, M.D.

1. IN acute rheumatism the heart is apt to be inflamed. Attention is usually concentrated on the membranes; but the muscular substance also suffers. When severe, myocarditis is apt to be fatal, and is frequently recognised in the post-mortem room. In a mild form it is, I believe, much more common than is usually supposed. It may exist independently of inflammation of the membranes. In all forms it produces softening and weakness of the muscular substance.

2. Salicylic acid, no matter whether given alone or in combination with soda, exercises a depressing action on the heart. This action is by no means general, and is probably due to some idiosyncrasy of the affected individuals.

3. If this depressing action be produced in one in whom the heart is physically sound, no great harm will be done.
With the omission of the drug the depression will soon pass off.

4. But if it be produced in one who is already the subject of rheumatic myocarditis (an ailment which is not easily recognised during life), and in whom therefore there exist softening and enfeeblement of the ventricular walls (for the left ventricle is the chief seat of such inflammation) the depression is likely to be alarming, and may be fatal.

To form an adequate estimate of the nature and extent of the dangers attendant on the administration of salicylic acid in acute rheumatism, we must recognise-first, the tendency of the rheumatic poison to produce inflammatory softening and weakness of the muscles of the heart; and, secondly, the tendency of salicylic acid to depress that organ. It is in the combination of these two that lies the danger of the drug.

It is in the absence of the tendency to produce such depression that lies the superiority of salicin over salicylic acid. Cadogan-place.

\section{dettirnor}

\section{HOSPITAL PRACTICE, BRITISH AND FOREIGN.}

Nulla autem est alia pro certo noscendi via, nisi quamplurimas et morborum et dissectionum historias, tum aliorum, tum proprias collectas habere, et inter se comparare.-Morgagni De Sed. et Caus, Morb., lib. iv. Procmium.

\section{GUY'S HOSPITAL.}

SURGICAL CASES ILLUSTRATING WOUND TREATMENT AND REPAIR.

(Under the care of Mr. BRYANT.)

Cancer of the Breast; Excision; Primary Union of Wound. (From notes by Mr. Dashwood.)-Mary Ann Waged fifty, was admitted into Lydia ward on July 16th, 1879. She was a married woman, but had had no children. Her menses had always been regular. About a month before she noticed a little milky discharge from the left nipple. She had occasional shooting pains, and in a week or two she noticed the nipple was retracted, and that there was a small swelling at the lower part of the left breast. The swelling slightly increased in size.

On admission she was a healthy-looking woman. She had two scars on the upper part of the left breast caused by a burn in childhood. At the lower part of the left breast, behind the nipple, was a hard, nodulated, movable tumour, about the size of a pigeon's egg. The skin was normal, and movable over the tumour. There were no enlarged glands, and no pain. The case was supposed to be one of cancer.

On July 22nd, while under chloroform, an exploratory cut was made, but no pus escaped. Two semicircular incisions were then made, enclosing the nipple, and directed obliquely downwards and inwards. The whole breast was removed. Several arteries were twisted, but there was not much hæmorrhage. The wound was washed with iodine and water, and the edges brought together with silk sutures and waterproof strapping; it was dressed with oil of turpentine. The wound healed by primary union, and she left on Aug. 14th.

Temperature Chart. - On July 22nd the temperature was $978^{\circ}$; after 8 P.M., $100 \cdot 2^{\circ}$. 23rd : Morning, $99^{\circ} 8^{\circ}$; evening, $98 \cdot 4^{\circ}$. 24th : Morning, $97.8^{\circ}$; evening, 100 $2^{\circ}$. 25th : Morning, $1006^{\circ}$; evening, $98^{\circ}$. From this time the temperature never rose more than one degree above normal.

Adenome of Breast; Excision; Repair by Primary Union. (From notes taken by Mr. Dashwood.)-Leah $\mathrm{S}-$ aged twenty-six, was admitted into Lydia ward on July 16th, 1879. She was a single woman, and had always enjoyed good health. About a year before she noticed a hard swelling upon the upper part of the right breast. Though it had not apparently increased in size, the skin over it turned blue, which caused her to apply at the hospital. The menses had been regular.

On admission there was a hard tumour, about the size of a hazel nut. The surface was flat, but the margins were nodulur. The tumour was freely movable, and the skin 